\title{
Effects of informal economy towards employment: A systematic review
}

\author{
Nor Amaleena Mazlan ${ }^{1}$, Rosilawati Zainol ${ }^{2}$, Yong Adilah Shamsul Harumain ${ }^{3}$ \\ ${ }^{1}$ Faculty of Built Environment, University of Malaya \\ ${ }^{2}$ Centre for Civilizational Dialogue, University of Malaya \\ ${ }^{3}$ Centre of Transportation Research, University of Malaya \\ Correspondence: Rosilawati Zainol (rosilawatizai@um.edu.my)
}

Received: 06 November 2020; Accepted: 22 May 2021; Published: 27 August 2021

\begin{abstract}
Throughout the years, the ultimate goals of sustainable development are progressing towards reducing poverty and social disparities. In realizing the economic advancement in sustainable development, this paper explores the informal economy's role in creating job opportunities. Few pieces of literature were examined to establish several themes. The existing literature on the informal economy's employment effects was analyzed by employing preferred reporting items for systematic reviews and meta-analyses (PRISMA) review method. Using Scopus and Web of Science as literature search databases, 27 publications have been identified and extracted. These publications were selected based on several criteria, including a timeline, language, publication type and publication stage. Throughout the process, four themes are identified, namely management and regulation, market competitiveness, people's welfare and productivity: with 13 sub-themes, namely regulation for workers, delicensing, local competition, product market, social stability, shelter, economic rights, marginalization, growth, income, tax burden unemployment and investment. These themes are selected through content analysis based on the regularity of these keywords appeared. Few recommendations highlighted the method of studies. Researchers are to conduct more qualitative studies and a standard systematic review technique in guiding data synthesizing. Finally, researchers are to adopt more searching strategies. This paper could contribute to the body of knowledge; in which the PRISMA method is essential for summarizing evidence on the effects of employment in a more accurate manner.
\end{abstract}

Keywords: Employment, Informal Economy, Poverty, PRISMA Method, Sustainable Development, Systematic Review

\section{Introduction}

An ideal concept of economically sustainable development suggests appropriate planning and coordination of development costs and benefits with conservation of social, environmental, cultural and waste reduction. However, an economic downturn faced by both developing and developed countries has stimulated peoples' interest in the informality scene of the economy; despite it being operated outside of the law. Early literature suggests that the community's 
increase in informal economy participation was primarily to evade taxes, lose government benefits, and avoid licensing and regulations requirements (Vuletin, 2008; Igudia et al., 2016). Moreover, the informal economy's development has generated multiple externalities towards the economy due to unregulated operations and productions.

Informal activities and services are known as symbolic of the informal economy in cities. These activities include street vendors, the most visible informal economy operated with a beneficial social purpose. Nevertheless, the informal economy's effects on sustainable economic development are seldom mentioned in many literary works (Bruton et al., 2012). O'Flaherty (2005) explained that the scale of financial returns is inter-dependent on the importance of society's activities. It acts as determinants towards the development of cities. As informal economies are formed due to poverty and low job opportunities, effective formalization strategies and actions are needed to facilitate the current activities. International Conference of Labour Statisticians (ICLS) has distinguished informal businesses as small and family-run or operated by a single entrepreneur. These enterprises are categorized into three different types of employment, which include: (1) "informal employment in informal sector, (2) informal employment in the formal sector; and (3) informal self-employed (OECD, 2011; Martinez et al., 2017). Informal employment in the informal sector represents informal businesses with informal employees operating illegally to avoid paying taxes.

In contrast, informal employment in the formal sector is defined as workers that do not go through the legal process with improper regulations, such as illegal immigrant workers. Informal self-employed workers refer to a self-employed worker who operates their businesses informally or working in a household that does not require formal processes such as maids and gardeners. However, there is no evident characteristics between formal and informal sector as major manufacturing companies and legal businesses have informal labour working for their proper businesses (Tokman, 2011). Therefore, this study explores the informal economy's effects on employment by systematically reviewing the literature on the informal economy's impact on employment.

\section{Systematic review framework on effects of informal economy towards employment}

The systematic review refers to an in-depth review of literature that pursues answers to a specific research question (Gough et al., 2012) by explicitly identifying, screening and assessing the study searches (Higgings et al., 2011). The term systematic review was first introduced in social sciences and has been widely acknowledged and adopted in other disciplines and fields. Despite the diverse application, the process of systematic review involves multiple steps, namely (1) defining the research question and scope of the study, (2) inclusion or exclusion of criteria in literature, (3) critical evaluation of the quality of the literature, (4) analyzing and synthesizing the evidence; and (5) presenting results (Petticrew \& Roberts, 2006; Barth \& Thomas, 2012).

Despite various literature and studies on employment in the informal economy, there are no systematic reviews that focus on the effects of employment on the informal economy. By employing the systematic review protocol in this study, specific guidelines could be established hence addressing the knowledge gaps through prior planning and documentation of methodical approach concerning employment in the informal economy. To date, there is no holistic, systematic review that captures the effects of the informal economy towards employment in a detailed structure, which makes it challenging to replicate and determine the validity and comprehensiveness of the study literature. Also, this study is vital towards exploring the importance of employment in today's society to address poverty. In line with the New Urban Agenda by the United Nations (UN, 2016), the contribution of employment 
towards growth in cities is significant in achieving sustainable development. One research question is developed toward building a systematic review: What are the informal economy's effects on employment?

This study attempts to analyze the existing literature on the effects of the informal economy on employment. This first section details the purpose of conducting a systematic review and the approach used in this study, namely the PRISMA (Preferred Reporting Items Systematic Reviews and Meta-Analysis) method. Analyzing and synthesizing the literature is further elaborated in the next section, with specific keywords being extracted. After the methodology section, the results of the analysis and future direction for research are explained.

\section{Methodology}

This section discusses the method used to extract the literature on the informal economy's effects on employment. PRISMA method is employed. Two electronic databases are used, namely Scopus and Web of Science (WoS), to explicitly abstract and analyze the relevant searches for this study. This process includes the articles' eligibility, the exclusion criteria, identification, screening, data abstraction and analysis.

\section{PRISMA}

In this study, the systematic review is done via PRISMA Statement (Preferred Reporting Items for Systematic Reviews and Meta-Analyses). The systematic literature review method reviewed articles based on a developed research question through straightforward ways to choose and appraise relevant literature about the study (Petticrew \& Roberts, 2006). It aims to explicitly trace search and synthesis literature related to past research in an organized and transparent process through a replicable process. Another definition of systematic review is Meta-narrative reviews (Wong et al., 2013). Adopting this method allows fellow researchers in the same field to identify the gaps of past and current studies, hence enabling future research guidance.

\section{Resources}

This study uses two primary electronic databases, namely Scopus and Web of Science (WoS). Scopus is Elsevier's research abstract and citation database consisting of 36,377 titles from approximately 11,678 publishers, which comprise a wide-ranging of fields: life sciences, social sciences, physical sciences, and health sciences. The second research database, Web of Science (WoS), is a subscription-based database that provides citation data for wide-ranging fields of studies produced by Clarivate Analytics. Today, there are 90 million research records that consist of journal articles, conference proceedings, and abstracts.

\section{Eligibility and exclusion criteria}

In this systematic review, there are few criteria of eligibility and exclusion are determined. The first criteria, namely literature type, the eligible literature include research articles, case studies, thesis and dissertation, while conference proceedings, books and book chapters are excluded in this review. In terms of language criteria, the literature written in English is eligible, while literature written in a non-English language is excluded in this review. In terms of the period in which the literature was published, the only reasonable timeline was six years, including years from 2014 to 2020 . This timeline is selected to systematically extract only the recent 
studies pertaining effects of the informal economy on employment. For the publication stage criteria, only the literature in the final stage of publication is eligible for this review, while articles in the press are excluded.

\section{Systematic review process}

This systematic review process was executed in January 2021. In this process, there are four stages involved, which includes (1) identifying keywords used for the relevant literature search, (2) screening, (3) eligibility and (4) review. In terms of identifying keywords, both thesaurus and previous studies play an essential role in determining similar keywords or phrases used to describe effects, informal economy, and employment. After detailed scanning, three duplicate records were removed. During the preliminary screening stage, a total of 199 articles from both Scopus and Web of Science (WoS) are eligible for review. After the critical screening of its eligibility and exclusion criteria, a total of 46 articles were eligible for this review. After the eligibility stage, it was found out that some of the articles did not focus on the effects of the informal economy on employment. Hence, 19 out of the 46 full-text articles are excluded. The final stage involved reviewing a total of 27 articles following themes and sub-themes.

\section{Data abstraction and analysis}

This section explores the final articles that are relevant to be assessed and analyzed. These last articles are studies that focus on the effects of the informal economy on employment. The data were abstracted by scrutinizing its abstracts and detailed readings on the full-text articles to determine suitable themes and sub-themes. After the data abstraction, qualitative analysis was conducted through content analysis to identify themes related to the informal economy's effects on employment. Content analysis is employed, in which the appearance of the particular content or keywords are coded and grouped to identify similar contents. The sub-themes were then established from the themes. The inclusion and the exclusion criteria are summarized in Table 1.

Table 1. The inclusion and exclusion criteria.

\begin{tabular}{lll}
\hline Criterion & Inclusion & Exclusion \\
\hline Timeline & $2014-2021$ & $<2014$ \\
Document Type & Journal Articles & $\begin{array}{l}\text { Journals (systematic review), book series, } \\
\text { book, book chapters, conference proceeding } \\
\end{array}$ \\
$\begin{array}{l}\text { Publication Stage } \\
\text { Language }\end{array}$ & Final & $\begin{array}{l}\text { Article in press } \\
\text { Non-English }\end{array}$ \\
\hline
\end{tabular}

\section{Results}

During the review process, four main themes and 13 sub-themes related to the informal economy's employment effects were identified. The main themes include (1) management (three sub-themes), (2) market competitiveness (two sub-themes), (3) people's welfare (four sub-themes) and (4) productivity (six sub-themes). The results presented a comprehensive analysis of the informal economy's effects on employment in the global context. The search string used for the systematic review process is shown in Table 2.

Three studies were conducted in the least developed countries, namely Uganda, Bangladesh and Cambodia (Young, 2018; Narula, 2019; Tanaka \& Hashiguchi, 2020). Fourteen studies were conducted in developed countries, namely the United States, the United 
Kingdom, Brazil, South Korea, Lithuania, Russia, Australia and Slovenia (Autrey et al., 2014; Williams \& Harodnik, 2015a; Williams \& Harodnik, 2015b; Kim \& Kim, 2016; Visser, 2017; Abdel-Latif et al., 2017; Milovanova et al., 2018a; Milovanova et al., 2018b; Kireenko \& Nevzorova, 2019; Keen \& Ride, 2019; Navickas et al., 2019; Fedotov et al., 2020; Bayar et al., 2020). In developing countries, 12 research have been identified to be relevant with effects of the informal economy towards employment, namely Malaysia, Brazil, South Africa, Turkey, Croatia, India, Pakistan, Indonesia and Colombia (Bosch \& Pretel, 2015; Tijdens \& Besamusca, 2015; Rothenberg et al., 2016; Williams \& Franic, 2016; Elveren \& Osgur, 2016; Tan et al., 2016; Shembavnekar, 2019; Dominguez, 2019; Ullah et al., 2019; Avenyo et al., 2020; Santoso \& Sriyana, 2020).

In terms of approach, only one study has adopted the qualitative approach, while the rest of the studies have adopted the quantitative and mixed-method approach. In terms of years of publication, one article was published in 2014, four articles in 2015, five articles in 2016, two articles in 2017, three articles in 2018, seven articles in 2019, and five articles published in 2020 .

Table 2. The search string used for the systematic review process.

\begin{tabular}{|c|c|}
\hline Databases & Keywords Used \\
\hline Scopus & $\begin{array}{l}\text { TITLE-ABS-KEY (("effect" OR "consequence" OR "impact” OR “outcome” OR } \\
\text { "result”) W/ ("informal” OR “unofficial" OR "unauthorised" OR “shadow” OR } \\
\text { "grey”) W/ ("econ*” OR “market”) AND (“employ*” OR “job” OR “work”)) }\end{array}$ \\
\hline Web of Science & $\mathrm{TS}=($ effects informal economy AND on employment $)$ \\
\hline
\end{tabular}

\section{Effects of informal economy towards employment}

This section emphasizes the informal economy's effects in global perspectives such as management and regulation, market competitiveness, people's welfare and productivity. Figure 1 shows the flow diagram of the systematic searching by adopting the PRISMA method.

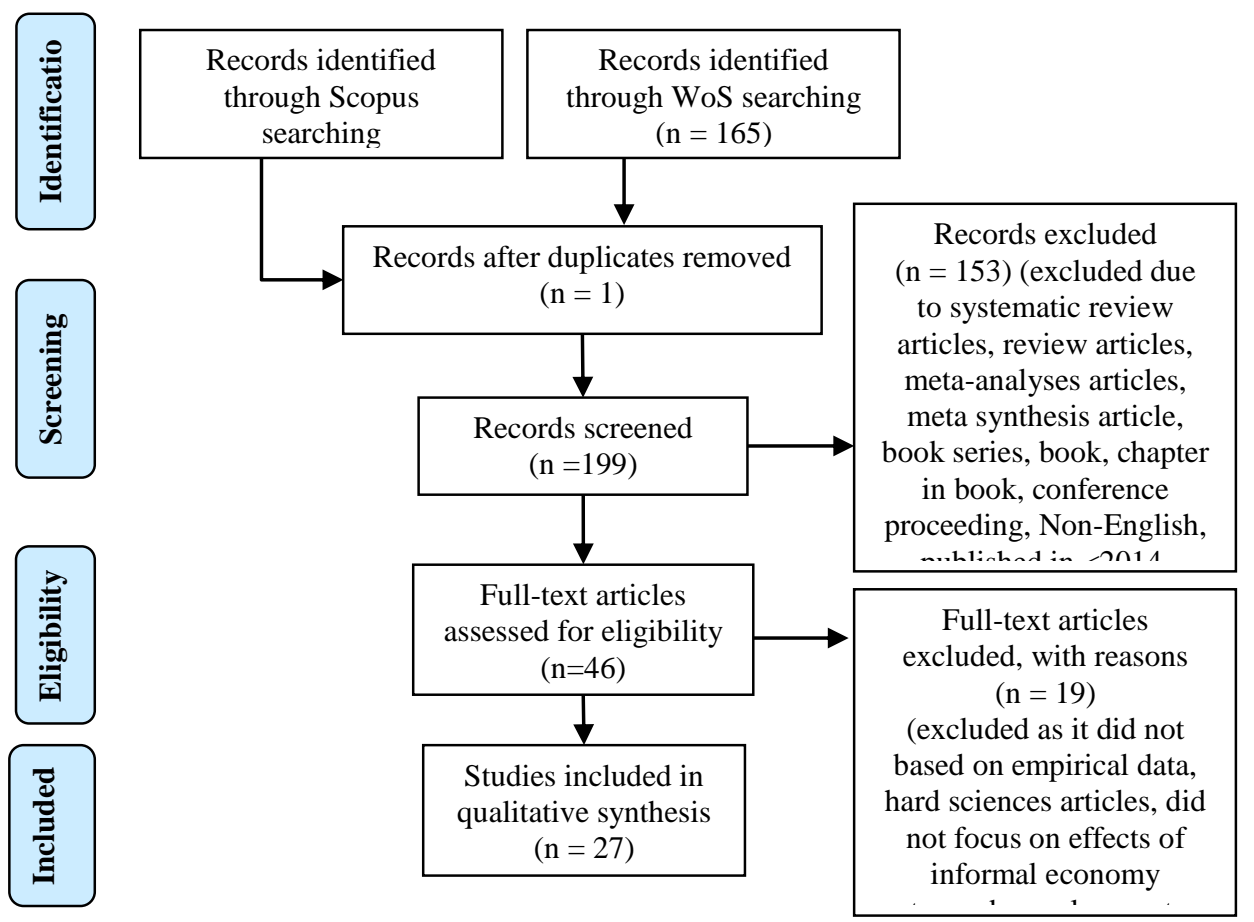

Source: Adapted from Moher et al. (2019)

Figure 1. The flow diagram of the study. 
Based on Figure 1, 35 and 165 articles are identified through SCOPUS and Web of Science searching, respectively. These articles are selected based on the inclusion and exclusion criteria with advanced search string as summarized in Table 1 and Table 2. After excluding systematic review articles, review articles, meta-analyses articles, meta-synthesis article, book series, book, chapter in book and conference proceedings, 46 articles are assessed for eligibility. 19 out of 46 articles are excluded as the articles did not focus on the informal economy's effects on employment, while the remaining 27 studies are selected for this review.

Based on Table 3, four themes are categorized based on their regularity of appearance in the articles. These themes are management and regulation, market competitiveness, people's welfare and productivity. The themes and sub-themes are summarised in Table 4.

\section{Management and regulation}

Based on Table 3, four out of 27 studies focused on management and regulation as the informal economy's employment effects. Three studies mentioned the elements of regulation towards workers, in which Visser (2017) explained that the regulation of informal workers would improve the employment outcomes for the marginalized individuals. Williams \& Franic (2016) believed that reducing the policies and institutional regulations are necessary to undertake the informal economy. Another set of authors, Williams \& Harodnik (2015), mentioned that informal workers' undeclared work increases the declared economy's disparities; hence, regulation is necessary. However, it is vital to acknowledge that informal businesses' reduction will take a more prolonged process. Thus, there is no quick solution that can amend informality (Rothenberg et al., 2016). The importance of the formal sector in businesses was put forward in a study conducted in South Africa. The formal sectors have been proven to provide protection in terms of high income and health benefits compared to the informal sector.

\section{Market competitiveness}

In terms of market competitiveness, two sub-themes are identified, namely local competition and product market. 10 out of 27 articles mentioned the elements of market competitiveness in their studies. Avenyo et al. (2020) explained that the informal economy had increased the competition among the local informal economy, thus increasing local products' innovation. Kireenko \& Nevzorova (2019) stated that the growth of the agricultural sector in the GDP would then increase the informal economy's growth. Another article was written by Elveren \& Osgur (2016) mentioned that income inequality and trade competitiveness are among the reasons behind the informal economy's establishment and the increase of unemployment contributed towards the informal economy. A study conducted by Narula (2019) in Dhaka, Bangladesh, reducing the informal labours in Multinational Enterprises has reduced businesses' growth and minimized job prospects. The informal sector's role in creating job opportunities has also been proven in another study in Cali, Colombia (Dominguez, 2019). In this study, approximately $60 \%$ of the workforce came from the informal sectors, as the informal economy was the only option for the less-educated workers on the edge of unemployment. This study has concluded that firms' productivity will increase in correlation to the number of job opportunities available within the firms' locations. Additionally, Dominguez (2019) also highlighted those informal businesses have lower human capital productivity levels as most of the informal businesses' locations are in low-density areas compared to formal businesses located in high-density locations profitable. 
Table 3. The findings sorted according by author, country and study themes.

\begin{tabular}{|c|c|c|c|c|c|c|c|c|c|c|c|c|c|c|}
\hline \multirow[t]{2}{*}{ Authors/ Countries } & \multirow{2}{*}{$\begin{array}{l}\text { Main } \\
\text { Study } \\
\text { Design }\end{array}$} & \multicolumn{2}{|c|}{$\begin{array}{l}\text { Management } \\
\& \text { Regulation }\end{array}$} & \multicolumn{2}{|c|}{$\begin{array}{c}\text { Market } \\
\text { Competitiveness } \\
\end{array}$} & \multicolumn{4}{|c|}{ People's Welfare } & \multicolumn{5}{|c|}{ Productivity } \\
\hline & & RW & DL & $\mathrm{LC}$ & PM & SS & $\mathrm{SH}$ & ER & MG & GR & INC & TB & UN & INV \\
\hline Avenyo et al. (2020) - South Africa & QN & & & I & / & & & & & / & & & & \\
\hline Bayar et al. (2020) - Lithuania & QN & & & & & & & & & I & & / & & / \\
\hline Santoso \& Sriyana (2020) - Indonesia & QN & & & & I & / & / & l & / & & & & / & \\
\hline Fedotov et al. (2020) - Slovenia & MM & & & & & I & I & I & & & I & & & \\
\hline Tanaka \& Hashiguchi (2020) - Cambodia & QN & & & & & & & & & & & & & \\
\hline Keen \& Ride (2019) - Australia & MM & & & & & I & I & l & I & I & & & / & \\
\hline Kireenko \& Nevzorova (2019) - Russia & QN & & / & / & l & & & & & & & & / & \\
\hline Narula (2019) - Bangladesh & QN & & & / & l & & & & & & & & & / \\
\hline Navickas et al. (2019) - Lithuania & QN & & & & & & & & & & & & / & \\
\hline Shembavnekar (2019) - India & QN & & & / & l & & & & & / & & & & \\
\hline Ullah et al. (2019) - Pakistan & QN & & & / & / & & & & & / & & & & \\
\hline Dominguez (2019) - Colombia & QN & & / & & I & & & & & & & & / & \\
\hline Milovanova et al. (2018) - Russia & QN & & & & & & & & & / & & & & / \\
\hline Milovanova et al. (2018) - Russia & QN & & & & I & & & & & & & / & / & \\
\hline Young (2018) - Uganda & MM & & & & & & & & & & & & & \\
\hline Abdel-Latif at al. (2017) - United Kingdom & QN & & & & & / & / & & & & & & & \\
\hline Visser (2017) - United States & MM & / & & & & & & & I & & & & & \\
\hline Tan et al. (2016) - Malaysia & QN & & & & & & & & & & & / & / & \\
\hline Elveren \& Osgur (2016) - Turkey & QN & & & I & & & & & & & I & & / & \\
\hline Rothenberg et al. (2016) - Indonesia & MM & & / & & & & & & & & & & & \\
\hline Williams \& Franic (2016) - Croatia & MM & / & & & & & & & & & & & / & \\
\hline Kim \& Kim (2016) - South Korea & QN & & & & & & & & / & l & / & & & \\
\hline $\begin{array}{l}\text { Williams \& Harodnik (2015) - United } \\
\text { Kingdom }\end{array}$ & QL & I & I & & & I & & & l & & & & & \\
\hline Tijdens \& Besamusca (2015) - South Africa & QN & / & & & & / & & & & & / & & & \\
\hline Bosch \& Esteban Pretel (2015) - Brazil & MM & & & & & / & & & & & & / & / & \\
\hline $\begin{array}{l}\text { Williams \& Harodnik (2015) - United } \\
\text { Kingdom }\end{array}$ & MM & & & & & & & & I & & & / & & \\
\hline Autrey et al. (2014) - United States & QN & & & / & l & & & & & / & & & / & \\
\hline
\end{tabular}

$\mathrm{QN}=$ Quantitative; $\mathrm{QL}=$ Qualitative $; \mathrm{MM}=$ Mixed Method 


\begin{tabular}{llll}
\hline Management \& Regulation & Market Competitiveness & People's Welfare & Productivity \\
\hline RW = Regulation for & LC = Local Competition & SS = Social Stability & GR = Growth \\
Workers & PM = Product Market & SH = Shelter & INC = Income \\
DL = Delicensing & & ER = Economic Rights & TB = Tax Burden \\
& & MG = Marginalisation & UN = Unemployment \\
& & INV = Investment \\
\hline
\end{tabular}

Table 4: The findings of the main and sub-themes.

\section{People's welfare}

Another theme identified as one of the effects of the informal economy on employment is people's welfare. Four sub-themes have been placed in this theme: social stability, shelter, economic rights, and marginalization. Based on a study by Fedotov et al. (2020) in Slovenia, the informal economy has contributed to social stability as it provides both employment, income and shelter. By eliminating the informal economy, the well-being of the people will decrease. According to Williams \& Harodnik (2015), the informal economy's undeclared jobs support the formal economy's disparities rather than reduce the disparities. Also, the informal economy acts as a solution, especially during tough times (Abdel-Latif et al., 2017; Keen \& Ride, 2019). However, with limited access to financial resources and security protection, people's welfare will decline (Santoso \& Sriyana, 2020). Another theme is marginalization. According to Tijdens \& Besamusca (2015), the informal workers are more likely to get paid below the minimum wage, working more than 48 hours and are not being insured.

\section{Productivity}

Out of 27 studies, 21 of the studies explained that improved productivity is one of the informal economy effects towards employment. Avenyo et al. (2020) pointed out the element of growth in their article, in which the improvement of sales can be witnessed within firms of the informal economy. However, the informal economy's enhancement will have adverse effects on legal firms' production and innovation. According to Amin \& Okou (2020), the informal economy's labour productivity is one-fourth of the formal economy. Milovanova et al. (2018) explained that both the investment activity and growth would increase at $10 \%$ and $7 \%$, respectively, on an annual basis, despite the decrease in the number of employees due to short term businesses. In terms of taxes, Bosch \& Esteban-Pretel (2015) explained that policies that provide low employment taxes and firing costs could produce a considerable decrease in informality and low unemployment rates. It would attract the persons who are involved in the informal businesses to shift to formal businesses. Some of the informal economy causes were discussed in this section, in which Tan et al. (2016) mentioned that the tax imposed by the Government has a positive impact on the informal economy, thus causing the increase in the informal sector's operations. Other than that, an increase in inequality in terms of income and foreign trade competitiveness has driven the development of the informal economy; in which the issue of unemployment was highlighted as one of the key factors contributing to the informal economy (Elveren \& Osgur, 2016; Navickas et al., 2019). 


\section{Discussion}

This study has systematically analyzed the existing literature on the informal economy's employment effects in the global setting. The informal economy refers to firms or businesses that operated without proper regulation. These businesses' results on employment should be studied to understand the informal economy's impacts on each community. A strenuous process of systematic review is conducted from two databases. It has resulted in 27 articles related to the effects of the informal economy on employment.

Based on the results, there are four main themes with 13 sub-themes that have been identified. The main themes are management \& regulation, market competitiveness, people's welfare and productivity. Eight out of 27 articles employed the mixed method in their studies, with 18 articles adopting the quantitative approach and only one article adopted the qualitative approach in their research. The results have shown the causes, benefits, structures, policies, and outcomes of informal economy operation in developed, developing and less developed countries.

Based on the analysis, the informal economy was established due to an increase in unemployment and acts as alternatives to the Government's tax burden towards the formal economy. As the informal economy contributes the most in less developed countries, few strategies were implemented and suggested. It includes a delicensing, unemployment benefits program, reducing the cost of formality.

\section{Future direction}

In this study, most of the articles reviewed adopted a quantitative method in which most of the studies are using questionnaire surveys and existing dataset to analyze their data. Future studies should consider adopting qualitative methods in their methodology as the qualitative approach provides an in-depth analysis of the informal economy's effects. Most of the studies rely on electronic keyword searches. This technique is considered as the best searching method for a systematic review; few techniques could be adopted, such as citation tracking. By adopting citation tracking, related articles can be identified by searching for reports based on citations. Another technique that could be used in the next future involves reference searching. This technique is done by analyzing the list of references in the selected articles for other articles. By examining the list of references, the risk of missing relevant information could be reduced.

\section{Conclusion}

This systematic review has focused on the importance of the informal economy towards employment in the global setting. This process has identified four themes: management \& regulation, market competitiveness, people's welfare, and productivity. Based on the systematic reviews performed, authors have identified 13 sub-themes concerning the informal economy's effects towards employment, namely, regulation for workers, delicensing, local competition, product market, social stability, shelter, economic rights, marginalization, growth, income, tax burden unemployment and investment. This review suggests few directions for future studies. More studies could be done in the qualitative method as it offers in-depth analysis and further explanation based on employment in the informal economy. Furthermore, few directions have 
GEOGRAFIA Online ${ }^{\mathrm{TM}}$ Malaysian Journal of Society and Space 17 issue 3 (194-205)

(C) 2021, e-ISSN 2682-7727 https://doi.org/10.17576/geo-2021-1703-14

been proposed for future studies, which include citation tracking and reference searching.

\section{References}

Abdel-Latif, H., Ouattara, B., \& Murphy, P. (2017). Catching the mirage: The shadow impact of financial crises. The Quarterly Review of Economics and Finance, 65, 61-70.

Autrey, R. L., Bova, F., \& Soberman, D. A. (2014). Organizational Structure and Gray Markets. Marketing Science, 33(6), 849-870.

Avenyo, E. K., Konte, M., \& Mohnen, P. (2020). Product innovation and informal market competition in Sub-Saharan Africa. Journal of Evolutionary Economics, 1-33.

Barth, M., \& Thomas, I. (2012) Synthesizing case-study research - Ready for the next step?. Environmental Education Research, 18(6), 751-764.

Bayar, Y., Remeikienè, R., Androniceanu, A., Gasparènienė, L., \& Jucevičius, R. (2020). The shadow economy, human development and foreign direct investment inflows. Journal of Competitiveness, 12(1), 5-21.

Bosch, M., \& Esteban-Pretel, J. (2015). The labor market effects of introducing unemployment benefits in an economy with high informality. European Economic Review, 75, 1-17.

Bruton, G. D., Ireland, R. D., \& Ketchen Jr, D. J. (2012). Toward a research agenda on the informal economy. Academy of Management Perspectives, 26(3), 1-11.

Dominguez, A. (2019). Agglomeration effects and informal firms in the internal structure of cities. Applied Economic Analysis, 27, 93-107.

Elveren, A. Y., \& Özgür, G. (2016). The effect of informal economy on income inequality: Evidence from Turkey. Panoeconomicus, 63(3), 293-312.

Fedotov, D. Y., \& Nevzorova, E. N. (2020). Intersectoral shadow economic linkages and their impact on tax evasion. Journal of Tax Reform, 6(1), 36-53.

Gough, D., Thomas, J., \& Oliver, S. (2012). Clarifying differences between review designs and methods. Systematic Reviews, 1(1), 28.

Håkansson, P., \& Nilsson, A. (2019). Getting a job when times are bad: Recruitment practices in Sweden before, during and after the Great Recession. Scandinavian Economic History Review, 67(2), 132-153.

Higgings, P. T., Altman, D. G., \& Sterne, A. C. (2011). Assessing risk of bias in included studies. Cochrane Handbook for Systematic Reviews of Interventions.

Igudia, E., Ackrill, R., Coleman, S., \& Dobson, C. (2016). Determinants of the informal economy of an emerging economy: A multiple indicator, multiple causes approach. International Journal of Entrepreneurship and Small Business, 28(2-3), 154-177.

Jiménez, A., Palmero-Cámara, C., González-Santos, M. J., González-Bernal, J., \& JiménezEguizábal, J. A. (2015). The impact of educational levels on formal and informal entrepreneurship. BRQ Business Research Quarterly, 18(3), 204-212.

Keen, M., \& Ride, A. (2019). Trading places: Inclusive cities and market vending in the Pacific Islands. Asia Pacific Viewpoint, 60(3), 239-251.

Kim, B. Y., \& Kim, M. J. (2016). The evolution of the informal economy in North Korea. Seoul Journal of Economics, 29(4), 457-480.

Kireenko, A. P., \& Nevzorova, E. N. (2019). Shadow economy in the countryside of Russian Regions. Regional Research of Russia, 9(1), 66-77. 
Martínez, L., Short, J. R., \& Estrada, D. (2017). The urban informal economy: Street vendors in Cali, Colombia. Cities, 66, 34-43.

Milovanova, E., Molodyh, V., Morozova, I., \& Ostapenko, E. (2018). Strategic planning features of regional development in increased exogenous volatility conditions. The Journal of Social Sciences Research, 4(12), 515-520.

Milovanova, E., Morozova, I., Molodyh, V., \& Ostapenko, E. (2018). Strategic supply chain planning of regional development in increased external instability conditions. International Journal of Supply Chain Management, 7(4), 330-336.

Narula, R. (2019). Enforcing higher labor standards within developing country value chains: Consequences for MNEs and informal actors in a dual economy. Journal of International Business Studies, 50(9), 1622-1635.

Navickas, M., Juščius, V., \& Navickas, V. (2019). Determinants of shadow economy in Eastern European countries. Scientific Annals of Economics and Business, 66(1), 1-14.

O' Flaherty, B. (2005). City Economics. Cambridge, MA: Harvard University Press.

Organization for Economic Co-operation and Development, \& Organisation for Economic Cooperation and Development Staff. (2011). OECD Employment Outlook 2011. Paris: OECD Publishing.

Petticrew, M., \& Roberts, H. (2006). Systematic reviews in the Social Sciences: A practical guide. Malden USA: Blackwell Publishing Cross.

Rothenberg, A. D., Gaduh, A., Burger, N. E., Chazali, C., Tjandraningsih, I., Radikun, R., ... \& Weilant, S. (2016). Rethinking Indonesia's informal sector. World Development, 80, 96113.

Santoso, R. P., \& Sriyana, J. (2020). The effect of idiosyncratic shocks on labor market outcomes of informal households in Indonesia. Jurnal Ekonomi Malaysia, 54(2), 1-14.

Shembavnekar, N. (2019). Economic reforms, labour markets and formal sector employment: Evidence from India. Economies, 7(2), 31.

Tan, Y. L., Habibullah, M. S., \& Yiew, T. H. (2016). The shadow economy in Malaysia: Evidence from an ARDL Model. International Journal of Economics \& Management, 10(2).

Tanaka, K., \& Hashiguchi, Y. (2020). Agglomeration economies in the formal and informal sectors: A Bayesian Spatial Approach. Journal of Economic Geography, 20(1), 37-66.

Tijdens, K., Besamusca, J., \& van Klaveren, M. (2015). Workers and labour market outcomes of informal jobs in formal establishments. A job-based informality index for nine SubSaharan African countries. The European Journal of Development Research, 27(5), 868886.

Tokman, V. E. (2011). Employment: The dominance of the informal economy. In The Oxford Handbook of Latin American Economics.

Ullah, S., Williams, C. C., \& Arif, B. W. (2019). The impacts of informality on enterprise innovation, survival and performance: Some evidence from Pakistan. Journal of Developmental Entrepreneurship, 24(03), 1-13.

Visser, M. A. (2017). Reshaping migrant labour market geographies: Local regularisations and the informal economy. Population, Space and Place, 23(7), e2025.

Vuletin, G. (2008). Measuring the informal economy in Latin America and the Caribbean. IMF Working Paper, 8(102). 
Williams, C. C., \& Franic, J. (2016). Explaining participation in the informal economy in PostSocialist Societies: A Study of the asymmetry between formal and informal institutions in Croatia. Journal of Contemporary Central and Eastern Europe, 24(1), 51-65.

Williams, C. C., \& Horodnic, I. A. (2015). Explaining and tackling the shadow economy in Estonia, Latvia and Lithuania: A Tax Morale Approach. Baltic Journal of Economics, 15(2), 81-98.

Williams, C. C., Horodnic, I. A., \& Windebank, J. (2015). Explaining participation in the informal economy: An institutional incongruence perspective. International Sociology, 30(3), 294313.

Wong, G., Greenhalgh, T., Westhorp, G., Buckingham, J., \& Pawson, R. (2013). RAMESES Publication Standards: Meta-narrative Reviews. BMC Medicine, 11(1), 20.

Young, G. (2018). De-democratisation and the rights of street vendors in Kampala, Uganda. The International Journal of Human Rights, 22(8), 1007-1029. 